\title{
Abelson Murine Leukemia Virus
}

National Cancer Institute

\section{Source}

National Cancer Institute. Abelson Murine Leukemia Virus. NCI Thesaurus. Code C14416.

A retrovirus that is associated with leukemia and induces in vitro transformation of certain mouse cells. 